Pedestrian Safety and Transit Corridors

\title{
Pedestrian Safety and Transit Corridors
}

\author{
Paul Mitchell Hess, University of Toronto \\ Anne Vernez Moudon, University of Washington \\ Julie M. Matlick, Washington State Department of Transportation
}

\begin{abstract}
This research examines the relationship between pedestrian accident locations on state-owned facilities (highways and urban arterials) and the presence of riders loading and alighting from bus transit. Many state facilities are important metropolitan transit corridors with large numbers of bus stops users, resulting in increased exposure of pedestrians to traffic and in increased numbers of collisions. The research also examines the association between pedestrian collisions and other travel generators (concentrations of retail activity and housing) as well as environmental conditions (wide roadways, high traffic volumes, and high speed limits).

Based on a retrospective sampling approach and logistic regression models, the study shows that bus stop usage is associated with pedestrian collisions along state facilities. Less strong, but significant associations exist between retail location and size, traffic volume, and number of traffic lanes, and locations with high levels of pedestrian-vehicle collisions. The findings suggest that facilities with high numbers of bus riders need to accommodate people walking safely along and across the roadway. They support the development of state DOT programs for multimodal facilities, which integrate travel modes in major regional facilities within local suburban communities and pay specific attention to the role of transit in shaping the demand for nonmotorized travel on the facilities.
\end{abstract}




\section{Problem Statement}

Collisions between motor vehicles and pedestrians along state highways with transit routes are associated with high rates of injury and death of pedestrians and constitute a significant societal problem. In Washington State more than 30 percent of vehicle-pedestrian collisions are not on city streets where travel on foot may be expected, but on large state roads that are typically considered regional or transregional facilities designed for moving traffic (Washington State Department of Transportation 1997). Between January 1995 and December 2000 state facilities accounted for over 1,795 collisions involving more than 1,995 pedestrians (Table 1). Of these, 175 pedestrians were killed and 376 disabled. Using federal and state cost formulas, average yearly societal costs were more than $\$ 100,000,000$.

Collisions are especially concentrated in metropolitan areas. King County, Washington's most urbanized county with 20 percent of the state's population, has a disproportionate number of pedestrian-vehicle collisions. With 56 pedestrian fatalities and 144 disabling injuries, the county accounts for 36 percent of state societal costs associated with pedestrian collisions over this same six-year period. Within King County, collisions are concentrated on State Route 99 (SR 99), which accounts for 43 percent of pedestrian vehicle collisions in the county and 16 percent for the state as a whole. Originally part of US 99, first commissioned in 1926 and stretching from Canada to Mexico, SR 99 became the urbanized region's second most important north-south thruway after the construction of Interstate 5 in the 1960s. Much of the corridor presents difficult and dangerous conditions for pedestrians. Development along the highway is strip commercial, the facility is wide with four to six travel lanes, traffic volumes are high, ranging from 20,000 to $40,0000 \mathrm{ADT}$, and large segments have no curbs and no sidewalks. It is also an important transit corridor.

Table 1. Reported Pedestrian Collisions on State Routes, 1995-2000

\begin{tabular}{|l|r|r|r|r|r|r|}
\hline & $\begin{array}{c}\text { Washington } \\
\text { State }\end{array}$ & \multicolumn{1}{c|}{$\begin{array}{c}\text { King } \\
\text { County }\end{array}$} & $\begin{array}{c}\text { SR99 in } \\
\text { King Co. }\end{array}$ & \\
\hline & $1995-2000$ & Avg. Yearly & $1995-2000$ & Avg. Yearly & $1995-2000$ & Avg. Yearly \\
\hline Collisions & 1795 & 299 & 670 & 112 & 289 & 48 \\
\hline Pedestrians & 1895 & 316 & 714 & 119 & 303 & 51 \\
\hline $\begin{array}{l}\text { Fatal } \\
\text { Injuries }\end{array}$ & 175 & 29 & 56 & 9 & 23 & 4 \\
\hline $\begin{array}{l}\text { Disabling } \\
\text { Injuries }\end{array}$ & 376 & 63 & 144 & 24 & 65 & 11 \\
\hline $\begin{array}{l}\text { Societal } \\
\text { Cost }\end{array}$ & $\$ 610,208,000$ & $\$ 101,701,333$ & $\$ 222,015,000$ & $\$ 37,002,500$ & $\$ 97,414,000$ & $\$ 16,235,667$ \\
\hline
\end{tabular}


State highways like SR 99 are common in many metropolitan areas. Designed for transregional traffic, these facilities have been lined with and surrounded by suburban development. As an alternative arterial street network was never developed (Untermann 1984; Southworth and Owens 1993), such regional facilities now also carry substantial local traffic. They even act as main streets, containing most of a community's retail, commercial, and institutional uses. The mismatch of facility design and current patterns of use may be an important reason why there are high collision rates in these places. The financial and political costs of converting highways back to their former, narrower purposes would be enormous, and it is thus important to understand the relationship between new use patterns and collisions.

Figure 1: Development along SR 99 north of Seattle. Regional highways have become urbanized roads with a variety of activities and uses.

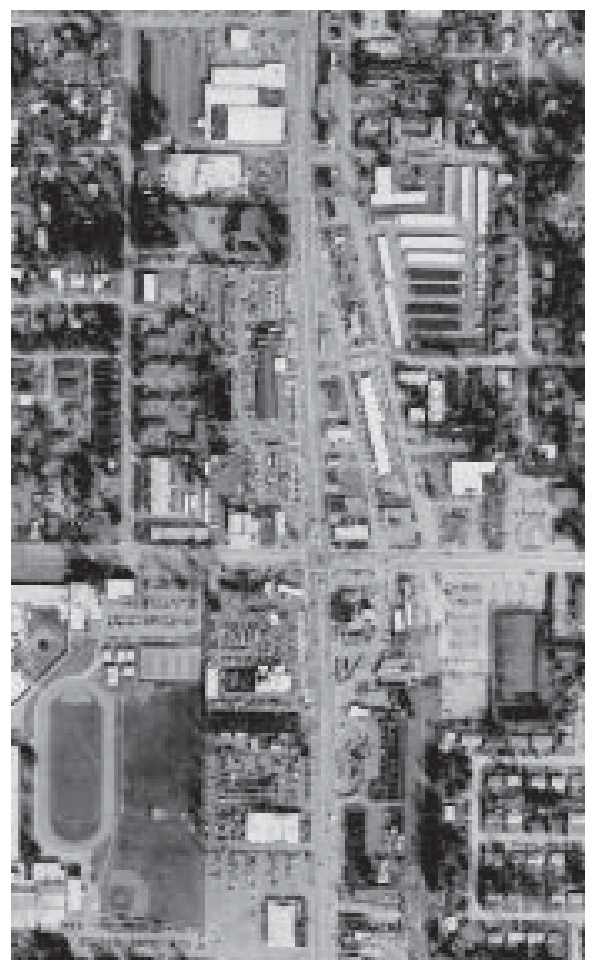


National, state, and local road design programs are being developed and implemented to address the growing demand for multimodal transportation on facilities of regional significance within metropolitan areas (U.S. Department of Transportation and Federal Highway Administration 2003; Florida Department of Transportation 2001; Huang, Stewart et al. 2001). Transit plays a significant role in generating pedestrian traffic on these highways, making it essential that facility design insure the safe integration of transit users with the driving public. This research supports the development of these programs and policies, and specifically the need for safety investments in regional traffic facilities that act as de facto transit and pedestrian zones.

\section{Research Objective}

The main purpose of this research is to examine the relationship between pedestrian accident locations on state facilities and the presence of riders loading and alighting from bus transit, controlling for other factors. Transit riders are pedestrians exposed to potential vehicle collisions. Transit commuters, for example, depart and return on opposite sides of roadways, necessitating at least one daily crossing. Large numbers of bus stops users are therefore likely to be associated with increased collisions. The research also examines other pedestrian travel generators, such as concentrations of retail activity and housing, as well as physical environmental conditions that affect pedestrian safety, such as wide roadways, high traffic volumes, high speed limits, traffic signalization, and crosswalk markings (Zegeer, Stewart et al. 2002; Koepsell et al. 2001).

The approach taken in this article differs from most previous safety research, which focuses on the increased risk of collision associated with facility characteristics while controlling for exposure. In other words, researchers have so far been interested in identifying unsafe conditions independent of the location and magnitude of pedestrian activity (Zegeer, Seiderman et al. 2002). This focus makes sense in areas where pedestrian volumes are high or evenly distributed along facilities, but it is less appropriate along state highways in suburbanized areas, where the presence of pedestrians tends to be sporadic. In these latter cases, the risk of collision is likely related not only to an interaction of pedestrian behavior and environmental factors, but also to actual pedestrian activity at certain locations. Unfortunately, data on the location and volume of pedestrian activity along sub-

urban highways are incomplete or missing. In response, this study uses data on 
locations with high numbers of pedestrian-vehicle collisions and examines whether these locations are associated with potential pedestrian generators. The argument is that limited resources for improving pedestrian safety make it essential to target public spending at the most dangerous locations. To do so requires an understanding of the links between pedestrian generators, most specifically bus stops, and pedestrian-vehicle collisions.

\section{Variables and Data Sources}

The study area for the project is the urbanized area of King County. Highway segments with large numbers of pedestrian-vehicle collisions are treated as the dependent variable. Indicators of pedestrian activity including bus stop usage and land uses that likely generate pedestrian traffic are treated as one category of independent variables. Roadway and facility conditions are treated as a second category of independent variables.

\section{Pedestrian-Vehicle Collision Locations}

Primary data are based on Pedestrian Accident Locations (PALs) identified by the Washington State Department of Transportation (WSDOT). WSDOT defines a PAL as four or more collisions over a six-year period along a 0.10 -mile section of roadway (528 feet). The concept of PAL was developed in transportation planning to identify highway segments that have large numbers pedestrian collisions. This research is first in using PAL to analyze underlying factors. PALs are used as the dependent variable because data on the precise locations of individual pedestrian collisions have not been available. Data on individual collisions would yield more analytical power, facilitating the use of nondichotomous variables and allowing for testing the effect of different spatial aggregations of collisions (beyond the 0.10 mile segments used).

For the 1995-2000 data period, 47 percent of the State's 120 PALs were located in King County (Table 2, Figure 2). King County PALs contained 55 percent of the total pedestrian collisions, 60 percent of fatalities, and 56 percent of disabling injuries located within all the PALs in Washington State. Because of large concentrations of PALs and continuously urbanized environmental conditions on SR 99, a separate analysis was done for this facility. SR99 contains 57 percent of PALS in King County and 27 percent of PALS in the State as a whole. Calculated societal costs for SR99 PALs average more than $\$ 10,000,000$ a year. 
Table 2. PALs, Constituent Injuries, and Costs in Washington State, King County, and SR99 in King County

\begin{tabular}{|l|r|r|r|r|r|r|}
\hline & $\begin{array}{c}\text { Washington } \\
\text { State }\end{array}$ & & $\begin{array}{c}\text { King } \\
\text { County }\end{array}$ & & $\begin{array}{c}\text { SR99 in } \\
\text { King Co. }\end{array}$ & \\
\hline & $1995-2000$ & Avg. Yearly & $1995-2000$ & Avg. Yearly & $1995-2000$ & Avg. Yearly \\
\hline \# of Pals & 120 & NA & 57 & NA & 33 & NA \\
\hline Collisions & 554 & 92 & 305 & 51 & 186 & 31 \\
\hline $\begin{array}{l}\text { Fatal } \\
\text { Injuries }\end{array}$ & 30 & 5 & 18 & 3 & 13 & 2 \\
\hline $\begin{array}{l}\text { Disabling } \\
\text { Injuries }\end{array}$ & 123 & 21 & 69 & 12 & 45 & 8 \\
\hline $\begin{array}{l}\text { Societal } \\
\text { Cost }\end{array}$ & $\$ 173,919,000$ & $\$ 28,986,500$ & $\$ 98,327,000$ & $\$ 16,387,833$ & $\$ 64,795,000$ & $\$ 10,799,167$ \\
\hline
\end{tabular}

\section{Indicators of Pedestrian Activity}

Indicators of pedestrian activity include bus stop usage, location of retail uses, concentrations of residences, and the locations of supermarkets, fast food restaurants, and school sites. It is hypothesized that these suburban pedestrian activity generators are positively associated with PAL sites. Data for bus stop usage are from METRO (the county transit agency) Automatic Passenger Counts (APC). Total daily boardings and alightings for each stop were averaged for two counting periods, fall 2000 and fall 2001. Land use data are from King County Assessor's data for each tax parcel attached to a geospatial database of approximately 500,000 parcels.

\section{Indicators of Roadways Conditions}

Data for roadways include traffic volumes, roadway width and number of lanes, traffic speed, and speed limits. As volumes, speeds, and roadway size increase, it is hypothesized that pedestrian risk, especially for street crossing, also increases. WSDOT geospatial (GIS) data on state highways were used for geocoding and mapping PALs. Data on traffic volumes as well as roadway attributes, such as travel lanes and posted speed limits, were obtained from the Puget Sound Regional Council (PSRC). All data were spatially overlaid and combined using GIS.

The number of intersections per one-half mile of linear roadway, or intersection density, was calculated from King County Network data using GIS and also used as an independent variable. Because the relationship between intersection density and environmental conditions is not well understood, the direction of the rela- 


\section{Figure 2. Pedestrian Accident Locations (PALs) on State Routes in King County}

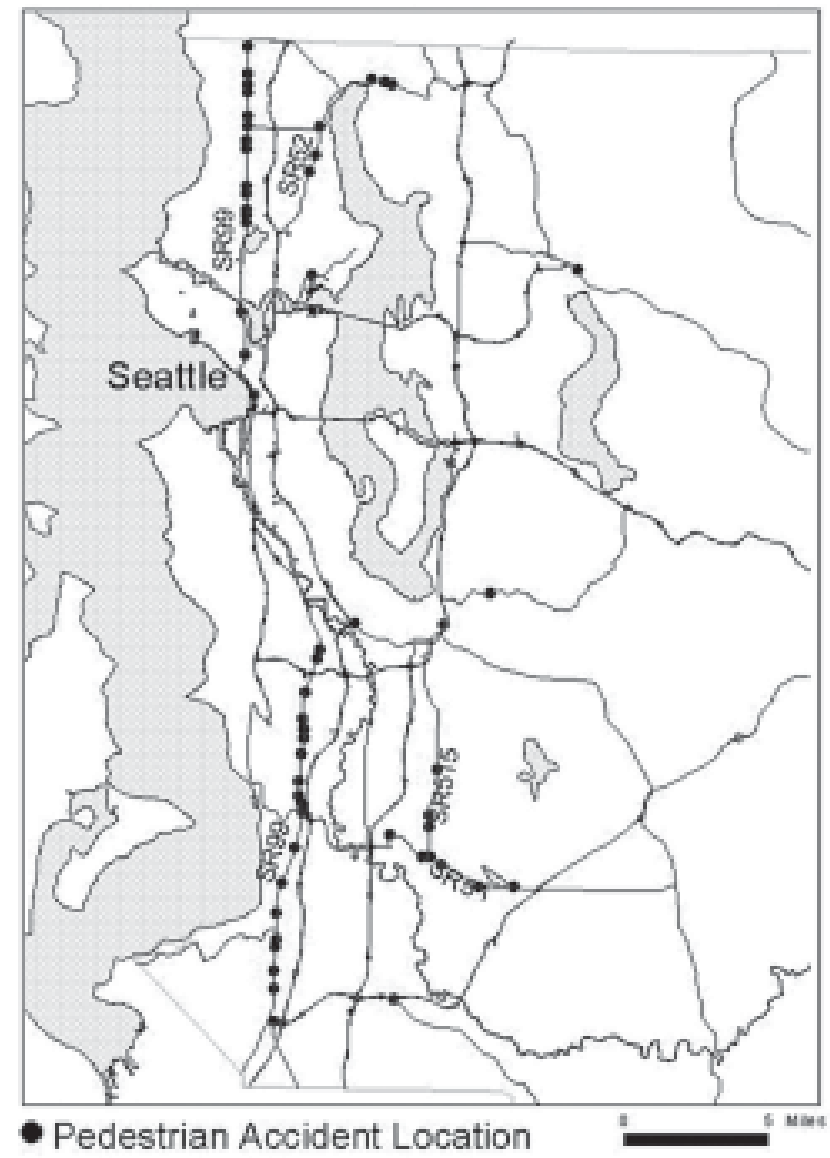

tionship to PALs was not hypothesized. High intersection density may increase pedestrian risk because of frequent vehicle turning movements. Yet very low intersection density may also increase risk: because signalized intersections are typically placed one-half mile apart or more in suburban environments, pedestrians may engage in risky mid-block highway crossings rather than choose to make the long walk to a protected crossing and back. 


\section{Research Design}

This research uses a retrospective sampling approach (Ramsey et al. 1994 ) to test variables for their power to distinguish between a set of predefined locations, in this case all PALs, and a set of other, randomly selected locations, in this case nonPAL sample points (hereafter referred to as "sample points"). Problems of spatial correlation precluded treating highways as a continuous series of points, and a limited number of sample points were drawn representing 0.10-mile segments. Sample points were not drawn along controlled or limited access facilities including large portions of SR 99 in the City of Seattle and Interstate 90. Approximately 50 sample points were drawn along SR 99 and 75 on other state facilities within the urbanized area (see Table 3).

Data for pedestrian activity generators and roadway characteristics were attached to each PAL and sample point. Bus boardings and alightings were aggregated for each 500-foot highway segment, approximately overlapping the length of 528foot PAL segments. Land-use generators, such as the total floor area of commercial uses, were measured based on walking sheds of one-quarter mile from the center of PALs and sample points. Housing unit densities were measured using a one-half mile figure as a proxy for the potential for generalized pedestrian activity. Table 4 describes the variables and the data sources used. The principal modeling technique was binary logistic regression. Analysis was performed on three sets of data: (1) all facilities, (2) SR 99, and (3) facilities other than SR 99. Separating SR 99 was justified because it is more substantially developed and used than other facilities, and contains a disproportionate number of PALs.

Table 3. PAL and Sample Points on SR99 and Other State Routes in King County

\begin{tabular}{|l|c|c|c|}
\hline & SR99 & $\begin{array}{c}\text { Other } \\
\text { State Routes }\end{array}$ & Total \\
\hline PALs & 33 & 23 & 56 \\
\hline Sample Points & 49 & 76 & 125 \\
\hline Total & 82 & 99 & 181 \\
\hline
\end{tabular}


Pedestrian Safety and Transit Corridors

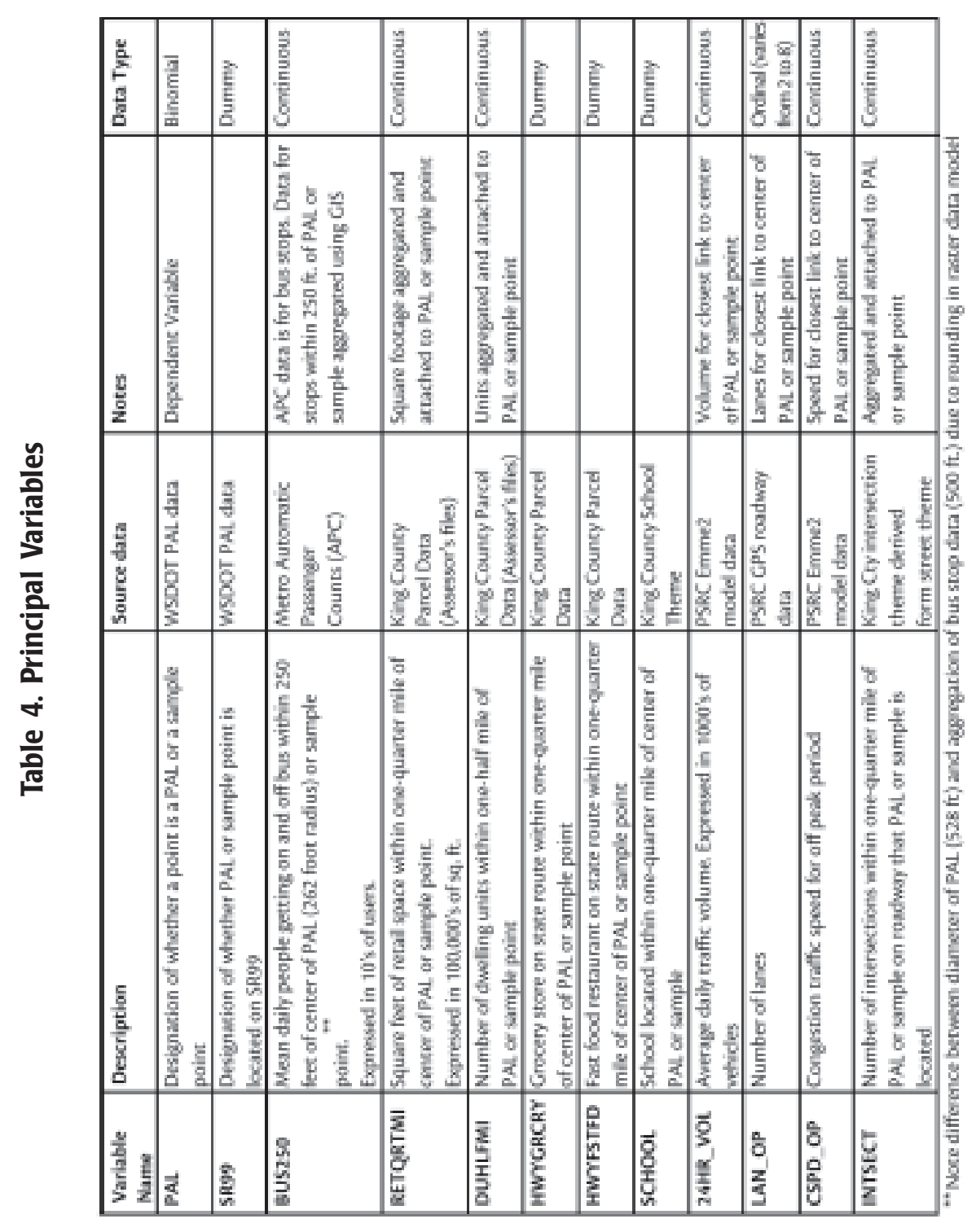




\section{Analyses and Findings}

Variables were examined in terms of their means and standard deviations. Correlation analysis was used to explore basic relationships between variables and test for multicolinearity.

\section{Descriptive Statistics}

Basic descriptive statistics PALs and sample points on all state facilities in King County and for SR99 are presented in Tables 5 and 6. Mean bus stop use within all PAL and sample points is 54 persons day. On SR 99 only, this about doubles to a mean of 101 persons. The areas around PALs and sample points are clearly urbanized, although substantial variation is found in the mean of 100,000 square feet of retail space within one-quarter mile. Compared to the entire data set, points along SR 99 have more housing units, with a mean of almost 2,000 within the buffer zones. Also, a higher percentage of SR 99 points are located near groceries, fast food restaurants, and schools. State facilities are heavily trafficked, with a mean of 40,000 daily vehicles for all PALs and sample points, and a mean of 57,000 on SR 99. SR 99 also has more travel lanes. Finally, both sets show mean off-peak speeds modeled at just over 30 miles an hour. They have similar numbers of intersections per one-quarter mile of highway, with a mean of about 4.6, or about one every 300 feet, but there is a fair degree of variation in this figure.

Table 5. Descriptive Statistics for PAL and Sample Points on All State Facilities in King County

\begin{tabular}{|l|c|c|c|c|c|}
\hline & N & Minimum & Maximum & Mean & Std. Deviation \\
\hline BUS250 & 181 & 0 & 93 & 5.4 & 12.88 \\
\hline RETQRTMI & 181 & 0 & 8.95 & 0.96 & 1.29 \\
\hline DUHLFMI & 181 & 0 & 5578 & 1536 & 1031 \\
\hline HWYGRCRY & 181 & 0 & 1 & 0.13 & 0.33 \\
\hline HWYFSTFD & 181 & 0 & 1 & 0.38 & 0.49 \\
\hline SCHOOL & 181 & 0 & 1 & 0.29 & 0.46 \\
\hline 24HR_VOL & 176 & 0.4 & 109.6 & 40.3 & 26.1 \\
\hline LAN_OP & 176 & 2 & 8 & 3.9 & 1.2 \\
\hline CSPD_OP & 176 & 12.1 & 44.7 & 31.5 & 5.9 \\
\hline INTSECT & 181 & 1 & 13 & 4.57 & 3 \\
\hline
\end{tabular}


Table 6. Descriptive Statistics for PAL and Sample Points on SR99 in King County

\begin{tabular}{|l|c|c|c|c|c|}
\hline & N & Minimum & Maximum & Mean & Std. Deviation \\
\hline BUS250 & 82 & 0 & 93 & 10.1 & 17.6 \\
\hline RETQRTMI & 82 & 0 & 8.95 & 1.17 & 1.47 \\
\hline DUHLFMI & 82 & 18.64 & 5578.104 & 1984.49511 & 1181.436518 \\
\hline HWYGRCRY & 82 & 0 & 1 & 0.16 & 0.37 \\
\hline HWYFSTFD & 82 & 0 & 1 & 0.46 & 0.5 \\
\hline SCHOOL & 82 & 0 & 1 & 0.38 & 0.49 \\
\hline 24HR_VOL & 82 & 12.9 & 109.6 & 57 & 24.6 \\
\hline LAN_OP & 82 & 2 & 8 & 4.5 & 1 \\
\hline CSPD_OP & 82 & 24 & 43.8 & 33.4 & 5.1 \\
\hline INTSECT & 82 & 1 & 13 & 4.9 & 3.3 \\
\hline
\end{tabular}

\section{Correlations}

Pearson correlation coefficients show that variables have only weak to moderate relationships with each other. Only two variables have Pearson coefficients above 0.5: 24-hour traffic volumes (24HR_VOL) with the number of dwelling units located within one-half mile of points (DUHLFMI) where the correlation is 0.51; and (24HR_VOL) with the number of travel lanes (LAN_OP) where the correlation is 0.69 . These and all other correlations make basic sense and do not present statistical problems.

\section{Logistic Regression}

Logistic regression was used due to the dichotomous nature of the dependent variable (whether a point is a PAL or not). The technique assesses other variables in terms of their power to predict the value of the dependent variable. In this case, the probability that a site is a PAL divided by the probability it is a non-PAL sample site (an odd ratio) is linearly regressed against the vector of the predictor variables. The exponential function of variable coefficients, Ex(B), can be interpreted as a multiplicative effect on the odd ratio of a one-unit change in the variable. The intercept cannot be interpreted. All variables were entered into the regressions. 


\section{Model 1: Results for ALL PAL and Sample Points in King County}

Model 1 is statistically significant at the 0.01 level (Table 7). The Cox and Snell R Square suggests that about a third of the variance in the dependent variable (whether a point is a PAL or not) is explained by the independent variables. Overall, 80 percent of total points are correctly predicted, with about 91 percent of non-PALs correctly predicted and only 57 percent of PAL correctly predicted.

Two variables are statistically significant: BUS250, the number of people boarding and alighting from bus within 250 feet of the center of a PAL or sample point expressed in tens of bus users; and RETQRTMI, the amount of building area in retail uses within one-quarter mile of the center of a PAL or sample point, expressed in 100,000s of square feet. The value of $\operatorname{Exp}(B)$ for BUS250 suggests increasing bus stop usage by 10 people increases the odds that a point will be a PAL by 1.17 times. This supports the principal hypothesis of the study that increased bus stop usage is positively related to Pedestrian Accident Locations. Likewise, with RETQRTMI the value of $\operatorname{Exp(B)~suggests~that~adding~100,000~square~feet~of~}$ retail uses (about the size of two grocery stores) increases the odds that a point will be a PAL by about 1.5. In addition to increased pedestrian activity, increased levels of retail activity may also be associated with environmental factors that increase risk such as large numbers of active driveways along highways. The research cannot separate these possible effects.

\section{Model 2: Results for SR99 PAL and Sample Points in King County}

Similar to the first model, Model 2 is statistically significant at the 0.01 level with about a third of the variation in the dependent variable explained (Table 8). Slightly better than the first model, Model 2 classifies about 75 percent of all points correctly, with 86 percent of non-PAL sample points and about 61 percent of PAL points correctly classified.

Bus stop usage is statistically significant, but unlike Model 1, retail activity (RETQRTMI) is not. The value of $\operatorname{Exp}(B)$ value suggests that an increase of 10 bus stop users increases the odds a site is a PAL by 1.16, similar to Model 1. The descriptive statistics for PAL and sample points helps explain these results (Table 9). On average, PALs have six times the bus stop usage of sample points, and about 50 percent more retail footage, but for all other variables, differences between PALs and sample points are slight. In other words, most points along SR 99 have similar conditions in terms of nearby land uses, traffic volumes and speeds, number of lanes, and intersection densities. The lack of variation in these variables urges cau- 
Table 7. Variables in Model 1 for All PAL and Non-PAL Sample Points in King County

\begin{tabular}{|l|c|c|c|c|c|}
\hline & B & S.E. & Wald & Sig. & Exp(B) \\
\hline BUS250 & 0.158 & 0.033 & 23.029 & $\mathbf{0}$ & 1.171 \\
\hline RETQRTMI & 0.398 & 0.195 & 4.165 & $\mathbf{0 . 0 4 1}$ & 1.489 \\
\hline DU1000 & 0.128 & 0.264 & 0.234 & 0.628 & 1.137 \\
\hline HWYGRCRY & -0.889 & 0.706 & 1.584 & 0.208 & 0.411 \\
\hline HWYFSTFD & 0.382 & 0.451 & 0.72 & 0.396 & 1.465 \\
\hline SCHOOL & 0.011 & 0.485 & 0.001 & 0.981 & 1.011 \\
\hline 24hr_VOL & -0.118 & 0.118 & 1.007 & 0.316 & 0.888 \\
\hline LAN_OP & 0.561 & 0.297 & 3.565 & 0.059 & 1.752 \\
\hline CSPD_OP & -0.03 & 0.041 & 0.541 & 0.462 & 0.97 \\
\hline INTSECT & 0.04 & 0.083 & 0.231 & 0.63 & 1.041 \\
\hline Constant & -3.22 & 1.486 & 4.698 & 0.03 & 0.04 \\
\hline & Chi-Sq. & DF & Sig. & likelihood & $\begin{array}{c}\text { Cox and } \\
\text { Sneel R Sq. }\end{array}$ \\
\hline Summary Stats. & 71.5 & 10 & 0 & 146.7 & 0.33 \\
\cline { 2 - 7 } & & & & & \\
\hline
\end{tabular}

Table 8. Variables in Model 2 for SR99 PAL and Non-PAL Sample Points in King County

\begin{tabular}{|l|c|c|c|c|c|}
\hline & B & S.E. & Wald & Sig. & Exp(B) \\
\hline BUS250 & 0.151 & 0.039 & 15.409 & $\mathbf{0}$ & 1.163 \\
\hline RETQRTMI & 0.332 & 0.246 & 1.828 & 0.176 & 1.394 \\
\hline DU1000 & 0.05 & 0.364 & 0.019 & 0.891 & 1.051 \\
\hline HWYGRCRY & -0.231 & 0.896 & 0.067 & 0.796 & 0.794 \\
\hline HWYFSTFD & -0.685 & 0.682 & 1.008 & 0.315 & 0.504 \\
\hline SCHOOL & 0.065 & 0.633 & 0.011 & 0.918 & 1.067 \\
\hline 24hr_VOL & -0.266 & 0.18 & 2.17 & 0.141 & 0.767 \\
\hline LAN_OP & 0.111 & 0.416 & 0.072 & 0.789 & 1.118 \\
\hline CSPD_OP & 0.018 & 0.071 & 0.063 & 0.801 & 1.018 \\
\hline INTSECT & 0.18 & 0.134 & 1.807 & 0.179 & 1.198 \\
\hline Constant & -2.243 & 2.306 & 0.946 & 0.331 & 0.106 \\
\hline Summary Stats & Chi-Sq. & DF & Sig. & $\begin{array}{c}-2 \text { log } \\
\text { likelihood }\end{array}$ & $\begin{array}{c}\text { Cox and } \\
\text { Sneel R Sq. }\end{array}$ \\
\cline { 2 - 7 } & 33.6 & 10 & 0 & 76.9 & 0.34 \\
\hline
\end{tabular}


tion in concluding that environmental conditions along the route do not contribute to pedestrian collision risk. Indeed the high concentrations of PALs suggest hazardous conditions along much of the highway's length to which the types of environments these variables proxy may contribute.

Table 9. Comparative Descriptive Statistics for PAL and Sample Points on SR99 in King County

\begin{tabular}{|c|c|c|c|c|c|c|}
\hline & & $\mathbf{N}$ & Minimum & Maximum & Mean & $\begin{array}{c}\text { Std. } \\
\text { Deviation }\end{array}$ \\
\hline \multirow[t]{10}{*}{ Sample Points } & BUS250 & 49 & 0 & 29 & 3.3 & 6.7 \\
\hline & RETQRTMI & 49 & 0 & 5.51 & 0.93 & 1.22 \\
\hline & DUHLFMI & 49 & 19 & 5578 & 1952 & 1356.7 \\
\hline & HWYGRCRY & 49 & 0 & 1 & 0.16 & 0.37 \\
\hline & HWYFSTFD & 49 & 0 & 1 & 0.45 & 0.503 \\
\hline & SCHOOL & 49 & 0 & 1 & 0.43 & 0.5 \\
\hline & 24HR_VOL & 49 & 17.1 & 109.6 & 57.6 & 26.8 \\
\hline & LAN_OP & 49 & 2 & 6 & 4.5 & 0.94 \\
\hline & CSPD_OP & 49 & 24 & 43.8 & 33.4 & 5 \\
\hline & INTSECT & 49 & 1 & 13 & 4.8 & 3.3 \\
\hline \multirow[t]{10}{*}{ PALS } & BUS250 & 33 & 0 & 93 & 20.2 & 23.3 \\
\hline & RETQRTMI & 33 & 0.05 & 8.95 & 1.52 & 1.74 \\
\hline & DUHLFMI & 33 & 665 & 4008 & 2032 & 876.5 \\
\hline & HWYGRCRY & 33 & 0 & 1 & 0.15 & 0.36 \\
\hline & HWYFSTFD & 33 & 0 & 1 & 0.48 & 0.51 \\
\hline & SCHOOL & 33 & 0 & 1 & 0.3 & 0.47 \\
\hline & 24HR_VOL & 33 & 12.9 & 103.6 & 56.1 & 21.3 \\
\hline & LAN_OP & 33 & 4 & 8 & 4.5 & 1.1 \\
\hline & CSPD_OP & 33 & 24 & 43.1 & 33.5 & 5.3 \\
\hline & INTSECT & 33 & 1 & 13 & 5 & 3.4 \\
\hline
\end{tabular}


Model 3: Results for Non-SR99 PAL and Sample Points in King County

Model 3 is statistically significant at the 0.01 level with almost half of the variation in the dependent variable explained. This is substantially higher than for the first two models. The model predicts about 90 percent of points correctly, with 94 percent of sample points and 74 percent of PALs correctly predicted. This is substantially higher than the SR 99 model. Table 10 shows four variables to be statistically significant at the 0.05 level. First, bus stop usage is significant, with an $\operatorname{Exp}(B)$ suggesting that an increase in usage by 10 people increases the odds that a site is a PAL by 1.5. Also significant is the dummy variable HWYGRCRY, indicating the presence of a grocery store but the coefficient is negative, opposite to the hypothesized direction of effect. However, the value of $\operatorname{Exp}(B)$ is extremely small at 0.003 with a 95 percent confidence interval ranging from 0.000 to 0.670 . It is not possible to interpret these results without further research.

Table 10. Variables in Model 3 for Non-SR99 PAL and Non-PAL Sample Points in King County

\begin{tabular}{|l|c|c|c|c|c|}
\hline & B & S.E. & Wald & Sig. & Exp(B) \\
\hline BUS250 & 0.415 & 0.185 & 5.031 & $\mathbf{0 . 0 2 5}$ & 1.515 \\
\hline RETQRTMI & 0.986 & 0.528 & 3.488 & 0.062 & 2.681 \\
\hline DU1000 & 0.287 & 0.659 & 0.19 & 0.663 & 1.333 \\
\hline HWYGRCRY & -5.658 & 2.682 & 4.45 & $\mathbf{0 . 0 3 5}$ & 0.003 \\
\hline HWYFSTFD & 0.043 & 1.074 & 0.002 & 0.968 & 1.044 \\
\hline SCHOOL & 3.27 & 1.895 & 2.977 & 0.084 & 26.311 \\
\hline 24hr_VOL & 0.621 & 0.292 & 4.529 & $\mathbf{0 . 0 3 3}$ & 1.861 \\
\hline LAN_OP & 2.726 & 1.306 & 4.361 & $\mathbf{0 . 0 3 7}$ & 15.276 \\
\hline CSPD_OP & 0.019 & 0.065 & 0.083 & 0.774 & 1.019 \\
\hline INTSECT & 0.258 & 0.272 & 0.902 & 0.342 & 1.295 \\
\hline Constant & -17.569 & 7.149 & 6.039 & 0.014 & 0 \\
\hline \multirow{2}{*}{ Summary Stats. } & Chi-Sq. & DF & Sig. & likelihood & Sneel R Sq. \\
\cline { 2 - 7 } & 63.6 & 10 & 0.00 & 41.03 & 0.49 \\
\hline
\end{tabular}


The final two significant variables are both related to traffic and roadway conditions. The value of $\operatorname{Exp}(B)$ for 24 -hour traffic volume (24hr_VOL) indicates the addition of 10,000 vehicles a day increases the odds a site is a PAL by 1.8. The value of $\operatorname{Exp}(B)$ for travel lanes (LAN_OP) suggests that each new travel lane increases the odds a roadway segment is classified as a PAL by more than 15 times. The direction of effect for both these variables is as hypothesized.

\section{Discussion}

All models show a positive relationship between bus stop usage and PAL sites and therefore support the principal hypothesis of the study. The SR99 model shows bus stop usage as the only statistically significant predictor of PALs. This maybe explained by the lack of variation in the other variables capturing pedestrian activity and road characteristics along the route. In addition to fairly high bus stop usage, SR99 has substantial retail activity, large numbers of housing units located along it, four to six travel lanes, and high traffic volumes-all factors that likely contribute to the large number of collisions and Pedestrian Accident Locations found along this roadway.

With more variations in the level of urbanization and in road characteristics, the non-SR 99 model suggests that traffic volumes and the number of traffic lanes are also statistically significant predictors of PALs. This is consistent with previous studies (Zegeer 1991). Because roadway widening is a common approach to dealing with the added traffic that comes with increased development, the potentially large effect of adding a traffic lane on the likelihood of creating a PAL deserves further research.

\section{Future Research}

PALs are practical and useful as a planning tool to direct safety dollars to specific locations along roadways. They also work as a measure of high-collision location associated with high bus usage. Yet at more than 500 feet in length, they are too large a spatial unit of data and analysis to research specific site conditions. PALs are not an effective dependent variable to model fine-grained differences in environments and the specific driver and pedestrian behaviors that may be associated with collisions-as, for example, modeling pedestrians crossing streets or turning vehicle movements. The length of a PAL also tends to smooth out variations in housing densities, retail area characteristics and other environmental attributes 
around collision sites, thus likely reducing the statistical power of modeling efforts. Further research must test different spatial aggregations of pedestrian collisions along routes and include such site-specific data on environmental conditions as sidewalks, crosswalks, and signalization.

The power of current GIS technology and analysis makes it possible to use small spatial units of analysis across large study areas (Steiner et al. 2002). To achieve this, new disaggregate data from both transportation and planning sectors are needed to increase analytical power. Although not available for this study, the eminent release of WSDOT data on individual collisions on all state and non-state roadways will make such analyses possible in the near future. The very high societal costs of collisions involving pedestrians bring urgency to the development of tools that define precisely where and how to invest safety dollars.

\section{Conclusions}

This study finds that the level of bus usage along state highways is significantly associated with high rates of pedestrian-vehicle collisions. In terms of policy, this result suggests that bus stops serving large numbers of riders should either be removed from state highways, or targeted for immediate safety improvements. Given the degree of urbanization and lack of other travel corridors in many metropolitan areas today, the former strategy is simply not realistic. Instead, facilities with high numbers of bus boardings or alightings must be designed to allow people to safely walk along and across the roadway.

It makes eminent sense to find that roads with high volumes of bus riders have more vehicle-pedestrian collisions than those with low ridership or no transit. Indeed, it may seem too obvious to researchers whose focus has been to identify factors affecting the relative risk of collision independently from the total number of pedestrians using given locations. Yet, this finding requires a rethinking of existing policies and institutional responsibilities to insure the safety of pedestrians on high-volume suburban corridors. It questions the appropriateness of current transit and highway safety programs that, to date, give low priority to the provision of safe facilities for transit riders walking to and from bus stops. It suggests that, in increasing their support of bus transit for roadway design and investment, safety programs within highway agencies place emphasis not only on the use of facilities by transit vehicle, but also on riders walking to and from those same vehicles. The finding also indicates that the responsibility of transit agencies to 
insure the safety of riders lies not only inside transit vehicles and at transit stops, but also extends to nearby locations along or across the road.

In metropolitan regions, high-volume state highways commonly lined with zones of strip-retail uses and active bus stops must be recognized as multimodal facilities. For these facilities, specific attention must be paid to the role of transit in shaping the demand for nonmotorized travel. Because many of these roadways have few or no pedestrian facilities, the relevant factor in improving their safety with limited resources is to target the locations where pedestrians are likely to be found. Safety investments should be directed to these locations. State DOTs, local jurisdictions, and transit staff must work together to identify facilities and locations where bus riders are at risk and take appropriate steps to insure pedestrian safety at and beyond bus stops.

\section{Acknowledgments}

The authors thank Dr. Jean-Yves Courbois for his help in designing the statistical analyses. 
Pedestrian Safety and Transit Corridors

\section{References}

Huang, H. F.; J. R. Stewart, and C. V. Zegeer. 2001. Evaluation of lane reduction "road diet" measures on crashes and injuries. Transportation Research Record 1784: 80-90.

Federal Highway Administration. 2003. Web site on Context-Sensitive Design Programs: http://www.fhwa.dot.gov/csd/index.htm.

Florida Department of Transportation. 2001. Florida intrastate highway systems multimodal corridor level of service analysis. June. http://www11.myflorida.com/ planning/systems/sm/los/pdfs/corridorfinalreport.pdf.

Koepsell T., L. McCloskey, M. Wolf, A. V. Moudon, D. Buchner, J. Kraus, and M. Patterson. 2001. Crosswalk markings and the risk of pedestrian motor vehicle collisions in older pedestrians. Journal of the American Medical Association 288 (17): 2136-2143.

Ramsey, et al. 1994. Habitat association studies of the northern spotted owl, sage grouse, and flammulated owl. In Case Studies in Biometry. Lange, N., Ryan L., Billard, L., Brillinger B., Conquest L., and Greenhouse J., eds. New York: John Wiley \& Sons.

Steiner, R. L., R. H. Schneider, and J. D. Moss. 2002. The promise and peril of pedestrian crash mapping: A study of eight Florida counties. Paper presented at the Transportation Research Board Conference (January).

Southworth, M., and P. Owens. 1993. The evolving metropolis: Studies of community, neighborhood, and street form at the urban edge. Journal of the American Planning Association 59 (3): 271-287.

Untermann, R. K. 1984. Accommodating the pedestrian: Adapting towns and neighborhoods for walking and bicycling. New York: Van Nostrand Reinhold Company.

U.S. Department of Transportation and Federal Highway Administration. 2003. Web site on Access Management. www.accessmanagement.gov.

Washington State Department of Transportation. 1997. Collision data 1990 to 1995. Olympia, WA: Planning and Programming Service Center, Transportation Data Office, March. 
Zegeer, C. V., J. Stewart, H. Huang, and P. Lagerwey. 2002. Safety effects of marked vs. unmarked crosswalks at uncontrolled locations-Executive summary and recommended guidelines. Report No. FHWA-RD-01-075. Washington, DC: Federal Highway Administration.

Zegeer, C. V, C. Seiderman, P. Lagerwey, M. Cynecki, M. Ronkin, and R. Schneider. 2002. Pedestrian facilities users guide-Providing safety and mobility. Report No. FHWA-RD-01-102, F. Washington, DC: Federal Highway Administration.

Zegeer, C. V. 1991. Synthesis of safety research: Pedestrians. Report No. FHWA-SA91-034. Washington, DC: Federal Highway Administration. 


\section{About the Authors}

Paul Hess (hess@geog.utoronto.ca) is assistant professor at the Department of Geography and Program in Planning at the University of Toronto. He has a B.A. in history, a Master in Urban Planning, and received his Ph.D. in urban design and planning in 2001 from the University of Washington, Seattle. His research focuses on transportation, especially pedestrian travel, and suburban development patterns. His work has been published in Transportation Research Record and the Journal of the American Planning Association.

Anne Vernez Moudon (moudon@u.washington.edu ) is professor of architecture, landscape architecture, and urban design and planning at the University of Washington, Seattle. She is president of the International Seminar on Urban Morphology (ISUF); faculty associate at the Lincoln Institute of Land Policy, in Cambridge, Massachusetts; fellow of the Urban Land Institute; and national advisor to the Robert Wood Johnson Foundation program on Active Living Policy and Environmental Studies. Dr. Moudon holds a B.Arch. (Honors) from the University of California, Berkeley, and a Doctor ès Science from the École Polytechnique Fédérale of Lausanne, Switzerland.

Julie Mercer Matlick (matlic@wsdot.wa.gov) manages the Community Partnership Program and the Context Sensitive Solutions project for the Washington State Department of Transportation. She has a background in downtown revitalization and economic development, and is a national expert on pedestrian design. She currently is the incoming president of the National Association of Pedestrian and Bicycle Professionals (APBP) and a member of TRB's Pedestrian Committee, ITE, and WTS. 